\title{
Autophagy and Ubiquitin-Mediated Proteolytic Degradation of PML/Rar $\alpha$ Fusion Protein in Matrine-Induced Differentiation Sensitivity Recovery of ATRA-Resistant APL (NB4-LR1) Cells: in Vitro and in Vivo Studies
}

\author{
Dijiong Wu ${ }^{a}$ Keding Shao ${ }^{b}$ Qihao Zhou ${ }^{c}$ Jie Sun ${ }^{d}$ Ziqi Wang ${ }^{b}$ \\ Fei Yan ${ }^{b}$ Tingting Liu ${ }^{b}$ Xiangping Wue Baodong Ye ${ }^{a}$ He Huang ${ }^{d}$ \\ Yuhong Zhou ${ }^{\mathrm{a}}$
}

\begin{abstract}
aDepartment of Hematology, First Affiliated Hospital of Zhejiang Chinese Medical University, Hangzhou, bFirst Clinical Medical College, Zhejiang Chinese Medical University, Hangzhou, 'Department of Hematology, Zhejiang Provincial People's Hospital, Hangzhou, dDepartment of Bone Marrow Transplantation, First Affiliated Hospital of Zhejiang University, Hangzhou, eDepartment of Pathology, First Affiliated Hospital of Zhejiang Chinese Medical University, Hangzhou, China
\end{abstract}

\section{Key Words}

Acute promyelocytic leukemia - ATRA-resistant $\cdot$ Autophagy $\cdot$ Differentiation - Matrine $\bullet$ PML-RAR $\alpha$ fusion protein • Ubiquitin

\footnotetext{
Abstract

Background/Aims: Although the cure rate of acute promyelocytic leukemia (APL) has exceeded $90 \%$, the relapse/refractory APL that resistant to all-trans retinoic acid (ATRA) or ATO was still serious concern. Matrine (MAT) could improve the differentiation ability of ATRA-resistant APL cells. This study aimed to explore how the APL-specific fusion protein was degraded in ATRA-resistant APL with the application of MAT and ATRA. Methods: ATRAsensitive (NB4) and ATRA-resistant (NB4-LR1) cell lines were used. Nitroblue tetrazolium reduction assay and flow cytometry were used to detect the differentiation ability. The activity of ubiquitin-proteasome and autophagy-mediated pathways in both cells treated with ATRA with or without MAT were compared in protein and mRNA level (Western blot analysis, qRT$P(R)$, the Fluorescent substrate Suc-LLVY-AMC detection was used to detect the activity of proteasome, and electron microscope for observing autophagosome. MG 132(proteasome inhibitor), rapamycin (autophagy activator), hydroxychloroquine (lysosomal inhibitor) and

D. Wu and K. Shao contributed equally to this work.

\begin{tabular}{ll}
\hline Dijiong Wu & First Affiliated Hospital of Zhejiang Chinese Medical University \\
and Baodong Ye & 54 Youdian Road, Hangzhou 310006, Zhejiang, China \\
& Tel. +86-13989463963, Fax +86-571-87073569, E-Mail wdj850@163.com, 13588453501@163.com
\end{tabular}
}




\section{Cellular Physiology Cell Physiol Biochem 2018;48:2286-2301

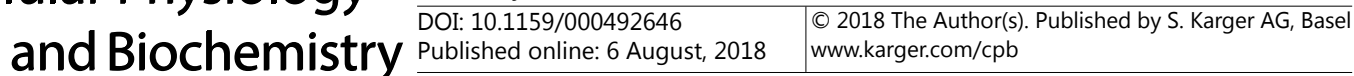 \\ Wu et al:: Mechanism of Matrine on Differentiation Recovery of ATRA-Resistant APL \\ Cells}

STI571 [retinoic acid receptor alpha (RAR $\alpha)$ ubiquitin stabilizer] were used as positive controls. The effect of MAT was observed in vivo using xenografts. Results: MAT improved the sensitivity of NB4-LR1cells to ATRA treatment, which was consistent with the expression of PML-RAR $\alpha$ fusion protein. MAT promoted the ubiquitylation level in NB4-LR1. MG 132 induced the decrease in RAR $\alpha$ in both cell lines, and hampered the differentiation of NB4 cells. MAT also promoted the autophagy in NB4-LR1 cells, with an increase in microtubule-associated protein 1 light chain3 (LC3)-II and LC3-II/LC3-I ratio and exhaustion of P62. The expression of LC3II increased significantly in the MAT and ATRA + MAT groups in combination with lysosomal inhibitors. A similar phenomenon was observed in mouse xenografts. MAT induced apoptosis and differentiation. Conclusions: Autophagy and ubiquitin-mediated proteolytic degradation of PML/RAR $\alpha$ fusion protein are crucial in MAT-induced differentiation sensitivity recovery of NB4-LR1 cells.

(C) 2018 The Author(s)

Published by S. Karger AG, Basel

\section{Introduction}

The major feature that distinguishes acute promyelocytic leukemia (APL) cells from other malignant hematopoietic cells is the expression of promyelocytic leukemiaretinoicacid receptor $\alpha$ (PML-RAR $\alpha$ ) fusion protein, which contributes to the inhibition of RAR $\alpha$-regulated hematopoietic cellular differentiation [1]. The complete remission rate of APL exceeded $90 \%$ with the application of all-trans retinoic acid (ATRA), arsenic trioxide (ATO), and anthracycline-based chemotherapy [2]. However, the 7-year cumulative incidence of relapses was reported as $28.6 \%$ in APL maintenance with ATRA and daunorubicin [3] and even reached $33 \%$ in the ATRA maintenance treatment group [4]. The relapse/refractory patients showed resistance to ATRA and/or ATO, which has been identified as a clinically significant problem. Currently, no effective drugs are available to reverse the ATRA resistance. Moreover, the mechanism of action of interferon- $\gamma$ and aurora kinase inhibitor is yet to be elucidated $[5,6]$.

Matrine (MAT) is the main active component of Sophora flavescens. It has been used to treat chronic hepatitis for several years in China [7]. Recently, the molecule has been proven to exhibit an anti-leukemic effect, including apoptosis induction through the mitochondrial pathway and protein kinase B (Akt) inactivation [8], and inhibit IL-6 receptor-mediated JAK/STAT3 pathway [9]. Previous studies have revealed that MAT can reverse the ATRA resistance of NB4-LR1 cells when coupled with ATRA. The treatment with $0.1 \mathrm{mmol} / \mathrm{L}$ MAT and $1 \mu \mathrm{mol} / \mathrm{L}$ ATRA can restore the ability of NB4-LR1 cells to differentiate, which might be related to the increased level of cyclic adenosine monophosphate and protein kinase $\mathrm{A}$ activity in NB4-LR1 cells, reduced telomerase activity and downregulated expression of topoisomerase II beta (TopoII $\beta)[10,11]$.

Subsequently, this study aimed to investigate the mechanism underlying the degradation of the PML/RAR $\alpha$ fusion protein in the presence of MAT and ATRA in NB4 and NB4-LR1 cell lines. It demonstrated the crucial role of autophagy and ubiquitin pathway in MAT-induced NB4-LR1 differentiation in vitro and tumor-bearing mouse model.

\section{Materials and Methods}

Cell line and culture

Both NB4 (ATRA-sensitive) and NB4-LR1 (ATRA-resistant) cell-lines were provided by Ruijin Hospital, Shanghai Institute of Hematology, China. All cells were cultured in RPMI -1640 culture medium (Gibco-BRL, USA) supplemented with $20 \%$ fetal bovine serum (Gibco-BRL) in a humidified incubator at $37^{\circ} \mathrm{C}$ with $5 \%$ $\mathrm{CO}_{2}$ in the air. 


\section{Cellular Physiology Cell Physiol Biochem 2018;48:2286-2301 and Biochemistry Published online: 6 August, $2018 \quad \begin{aligned} & \text { DOI: 10.1159/000492646 } 2018 \text { The Author(s). Published by S. Karger AG, Basel } \\ & \text { www.karger.com/cpb }\end{aligned}$ Wu et al.: Mechanism of Matrine on Differentiation Recovery of ATRA-Resistant APL Cells}

\section{Cell differentiation assays}

The appropriate concentration of ATRA (Sigma, USA) and MAT $\left(\mathrm{C}_{15} \mathrm{H}_{24} \mathrm{~N}_{2} \mathrm{O}, 98 \%\right.$ purity, Nanjing Zelang Chinese Medicine Science and Technology Co. Ltd., China) was $1 \mu \mathrm{mol} / \mathrm{L}$ and $0.1 \mathrm{mmol} / \mathrm{L}$, respectively, as described in a previous study [10]. For cell differentiation assays, seven groups were included: control group treated with phosphate-buffered saline (PBS); ATRA ( $1 \mu \mathrm{mol} / \mathrm{L})$ - treated (ATRA) group, MAT (0.1 mmol/L)-treated (MAT) group, MAT and ATRA-co-treated (ATRA+MAT) group; ATRA and MG132 (1 $\mu \mathrm{mol} / \mathrm{L}$, proteasome inhibitor, Sigma, USA)-co-treated (ATRA+MG) group; ATRA and Rapamycin (100 nmol/L, autophagy activator, Sigma)-co-treated (ATRA+RAPA) group; ATRA and STI571 (5 $\mu \mathrm{mol} / \mathrm{L}$, RAR $\alpha$ ubiquitin stabilizer, Sigma)-co-treated (ATRA+STI) group; MAT and MG132-co-treated (MAT+MG) group; MAT, ATRA and MG132-co-treated (ATRA+MAT+MG) group; MAT, ATRA and hydroxychloroquine (16 $\mu \mathrm{mol} / \mathrm{L}$, lysosomal inhibitor, Sigma)-co-treated (MAT+ATRA+HCQ) group. MAT and ATRA were diluted in PBS (Gibco) and dimethyl sulfoxide (Sigma), respectively, before use. Cell suspensions $\left(10^{5} / \mathrm{mL}\right.$ in complete medium) were incubated with the substances mentioned for 72h, except STI571 and HCQ which were added in the last $24 h$.

For the nitroblue tetrazolium (NBT) reduction assay, the treated cells were harvested, and cell suspensions $\left(10^{5}\right.$ cells $/ \mathrm{mL}$ in complete medium) were incubated with NBT $(1 \mathrm{mg} / \mathrm{mL}$, Sigma) and 12- $O$-tetradecanoyl-phorbol-13-acetate (TPA, $1 \mu \mathrm{g} / \mathrm{mL}$, Sigma) for $30 \mathrm{~min}$ at $37^{\circ} \mathrm{C}$. NBT was evaluated as the intensity of reduction measured at a wavelength of $570 \mathrm{~nm}$ using a microplate reader (Bio-Rad Model 680, USA). To measure the cell surface expression of differentiation marker CD11b, the cells were washed two times with PBS $\left(5 \times 10^{5}\right.$ cell/ tube) and stained with anti-CD11b-APC or IgG-APC isotypic control (BioLegend, Inc. CA, USA) for $30 \mathrm{~min}$ at $4^{\circ} \mathrm{C}$. Subsequently, the samples were washed two times and measured using flow cytometry (FACS Calibur, Becton Dickson, NJ, USA) by acquiring 10, 000 cells per test.

\section{Ubiquitin-proteasome pathway assays}

For the ubiquitin-proteasome pathway (UPP) assays, eight groups were prepared as follows: control group treated with PBS; ATRA group; MAT group; ATRA+MAT group; MG132 (1 $\mu$ mol/L)-treated group (MG); ATRA+MG group; MAT+MG group and ATRA, MAT, and MG132 multitreated group (ATRA+MAT+MG). Then, $10^{5}$ cells $/ \mathrm{mL}$ in complete medium were incubated with the aforementioned substance, respectively for $72 \mathrm{~h}$. The expression of proteasome 20S core subunits (pAb) and ubiquitin protein (Ub) was detected using the Western-blot analysis. The 20S proteasome activity was detected using a fluorescent substrate Suc-LLVY-AMC Detection Kit and the expression of $U b$ gene was detected using real-time polymerase chain reaction (PCR) as described later.

\section{Autophagy pathway assays}

For the autophagy pathway assays, seven groups were included as follows: control group (treated with PBS), ATRA group, MAT group, ATRA+MAT group, ATRA + MG group, ATRA and Rapamycin (100 nmol/L)co-treated (ATRA+RAPA) group, and ATRA + STI group. To detect the autophagic flux, the following groups were set up: control group, ATRA group, MAT group, ATRA + MAT group, MAT + HCQ and ATRA + MAT + HCQ group. The Western blot analysis was used for detecting the expression of autophagy-related proteins, including LC3, Atg1, PI3KC3, Atg5, and P62. An electron microscope (JEOL3010, MA, USA) was used to compare the autophagosomes among groups.

\section{Fluorescent substrate Suc-LLVY-AMC detection}

The activity of proteasome was detected using a fluorescent substrate Suc-LLVY-AMC (AAT Bioques, USA). The cells were harvested, washed three times with ice-cold PBS and lysed on ice with lysis buffer (10mM Tris pH 7.5, 130mM NaCl, 1\% NP-40, 10mM NaPPi, $1 \mathrm{mM}$ PMSF, $0.1 \mathrm{mM} \mathrm{Na}_{3} \mathrm{VaO}_{4}$ ). The lysates were precleared by centrifugation at $11,900 \mathrm{~g}$ for $15 \mathrm{~min}$ at $4^{\circ} \mathrm{C}$. The protein concentrations were determined using Bradford reagent according to the manufacturer's protocol. Each sample was incubated with $100 \mu \mathrm{L}$ of reaction solution [ $25 \mathrm{mmol} / \mathrm{L}$ HEPES (pH 7.5), $0.5 \mathrm{mmol} / \mathrm{L}$ EDTA, 0.05\% NP-40, and 0.001\% sodium dodecyl sulfate $(\mathrm{w} / \mathrm{v})]$ for $1 \mathrm{~h}$ at $37^{\circ} \mathrm{C}$. The protein content of each sample was $10 \mu \mathrm{g}$, and the final concentration of Suc-LLVY-AMC was $50 \mu \mathrm{mol} / \mathrm{L}$. A positive control group $(1 \mu \mathrm{mol} / \mathrm{L} \mathrm{MG132})$ and a negative control group were also set up. After hydrolysis, the fluorescence intensity at $380 \mathrm{~nm}$ (excitation) and $460 \mathrm{~nm}$ (emission) was measured using the Spectra Max M2 microplate reader (iMark, BIO-RAD, CA, USA). 


\section{Cellular Physiology Cell Physiol Biochem 2018;48:2286-2301 \begin{tabular}{ll|l} 
and Biochemistry Published online: 6 August, 2018 & $\begin{array}{l}\text { C } 2018 \text { The Author(s). Published by S. Karger AG, Basel } \\
\text { www.karger.com/cpb }\end{array}$ \\
\hline
\end{tabular} \\ Wu et al.: Mechanism of Matrine on Differentiation Recovery of ATRA-Resistant APL \\ Cells}

Western blot analysis

The cells were harvested, washed three times with ice-cold PBS and lysed on ice with lysis buffer (10mM Tris pH 7.5, 130mM NaCl, 1\%NP-40, 10mM NaPPi, $1 \mathrm{mMPMSF}$, and $0.1 \mathrm{mM} \mathrm{Na}_{3} \mathrm{VaO}_{4}$ ). The lysates were transferred to microcentrifuge tubes and precleared by centrifugation at $11,900 \mathrm{~g}$ for $15 \mathrm{~min}$ at $4^{\circ} \mathrm{C}$. Protein concentrations were determined using Bradford reagent according to the manufacturer's protocol. $\beta$-actin was used as an internal reference control. An equal amount of total protein extracted from cultured cells was separated using 12\% SDS polyacrylamide gel electrophoresis gel and transferred to polyvinylidene difluoride (PVDF) membranes (EMD Millipore Corporation, MA, USA). Primary antibodies and horseradish peroxidase conjugated appropriate secondary antibodies were used to detect the designated proteins. The secondary antibodies bound on the PVDF membrane were reacted with the enhanced chemiluminescence detection reagents (Beyontime, Institute of Biotechnology, Jiangsu, China) and exposed to x-ray films (Kodak, Japan). The result was analyzed using Image J 1.46r software. Anti-Ub, anti-ATG5, anti-LC3 and anti-P62 antibodies (CST, USA); anti-Atg1 and anti-PI3KC3 antibodies (Abcam, England); anti-pAb antibody (Enzo, USA); anti-TRIM32 polyclonal antibody (Proteintech, USA); anti-PML+RAR $\alpha$ fusion antibody (abcam, USA); anti-RAR $\alpha$ (Santa cruz, USA); anti-PML (Affinity, USA), and $\beta$-actin antibodies (LiankeBio, China) were used in the experiments.

\section{RNA isolation and quantitative PCR analysis}

Total RNA was isolated using TRIzol (Invitrogen) according to the manufacturer's protocol. The quality and concentration of RNA were evaluated using a spectrophotometer (NanoDrop 2000, Thermo, USA). Total RNAs were first reverse transcribed into cDNAs. The cDNAs were thereafter subjected to real-time reverse transcription PCR. After an initial denaturation step at $95^{\circ} \mathrm{C}$ for $10 \mathrm{~min}$, PCR cycling conditions were set as follows: denaturation at $95^{\circ} \mathrm{C}$ for $30 \mathrm{~s}$, annealing at $95^{\circ} \mathrm{C}$ for $5 \mathrm{~s}$, and extension at $60^{\circ} \mathrm{C}$ for $130 \mathrm{~s}$ for 40 cycles. After amplification, a melting-curve analysis was performed. The relative gene expression was analyzed using the $2^{-\Delta \Delta C \mathrm{Ct}}$ method. The primers for targeted genes were as follows. PML-RAR $\alpha$ : 5'-TCGAGTTCACCAGCAATGAG -3' (forward) and 5'-ATCGTACACCTCCGTCTCCA-3' (reverse); PML: 5'-TCTACGAGCTGTATGACGATGT-3' (forward) and 5'-CTGAGGGCGCTTCATCTCTG-3' (reverse); C/EBPE: 5'-GACCTACTATGAGTGCGAGCCT-3' (forward) and 5'-ACACCCTTGATGAGGGTAGCAG-3' (reverse); STAT-1: 5'-GGAGGCGAACCTGACTTCA-3' (forward) and 5'-TCTGGTGCTTCCTTTGGCCT-3' (reverse); c-Myc: 5'-CCACAGCAAACCTCCTCACAG-3' (forward) and 5'-GCAGGATAGTCCTTCCGAGTG-3' (reverse); glyceraldehyde-3-phosphate dehydrogenase (GAPDH): 5' - AGAAGGCTGGGGCTCATTTG -3' (forward) and 5'- AGGGGCCATCCACAGTCTTC -3' (reverse).

\section{Electron microscopic observation}

The cells were harvested, washed with PBS two times $\left(4^{\circ} \mathrm{C}, 300 \mathrm{~g}\right.$ for $\left.8 \mathrm{~min}\right)$, and moved to $1.5 \mathrm{~m} \mathrm{LEP}$ tubes. The samples were washed with PBS three times (15 min/time) and then fixed in 1\% osmic acid (60 $\mathrm{min}$ ) and $2 \%$ uranyl acetate (30 min). After dehydration in a gradient ethanol series, the cells were permeated with pure acetone and embedding medium (1:1) for $60 \mathrm{~min}$, and then permeated with embedding medium alone for another $60 \mathrm{~min}$. The conglomerate was dried in an oven, $37^{\circ} \mathrm{C}$ for $24 \mathrm{~h}, 45^{\circ} \mathrm{C}$ for $24 \mathrm{~h}$ and $60^{\circ} \mathrm{C}$ for $48 \mathrm{~h}$. Ultrathin sections $(0.1 \mu \mathrm{M})$ were prepared and examined under TECNA 10 transmission electron microscope (Philips, Holand). Autophagosomes were identified and counted with randomly selected six cells from each group.

\section{APL xenografts}

Animal studies were performed according to the National Institute of Health Guide for the Care and Use of Laboratory Animals under a protocol approved by the ethical committee of the hospital on December 24, 2012 (No. 2012-K-022-01). Twenty male BALB/c nude mice (animal No. 2008001649754) aged 4 weeks were purchased from Shanghai Sippr-B\&K Laboratory Animal Co. Ltd. (Shanghai, China) and were bred by Zhejiang Academy of Medical Sciences under specific-pathogen-free conditions. NB4 and NB4-LR1 cells, at a density of $1 \times 10^{7} / \mathrm{mL}$ in $200 \mu \mathrm{L}$ were implanted by subcutaneous into the right shoulder of mice. The mice were monitored daily, and after 8 days, the nude mice with implanted tumor were screened for the tumor volume. The mean tumor diameters (MTDs) were measured with Vernier caliper (MTDs=the product of the diameters of the vertical cross sections of tumor/2). Tumor-bearing mice in which the tumor MTD reached $2 \mathrm{~mm}$ were selected and randomly divided into four groups. The animals should be pair matched so that the median tumor volume for each group was similar. Each treated group was administered with $25 \mathrm{mg} / \mathrm{kg}$ 


\section{Cellular Physiology Cell Physiol Biochem 2018;48:2286-2301 \\ and Biochemistry Published online: 6 August, $2018 \quad \begin{aligned} & \text { DOI: 10.1159/000492646 } 2018 \text { The Author(s). Published by S. Karger AG, Basel } \\ & \text { www.karger.com/cpb }\end{aligned}$ \\ Wu et al.: Mechanism of Matrine on Differentiation Recovery of ATRA-Resistant APL \\ Cells}

body weight of ATRA or $38 \mathrm{mg} / \mathrm{kg}$ body weight of MAT or ATRA and MAT intraperitoneally (the dose of MAT and ATRA was converted by the body surface area according to the clinical application). The control group received $0.9 \%$ normal saline at the same volume as in the treated groups. The corresponding agent of each group was given once per day for the next 3 weeks. After the mice were executed, tumors of each group were excised, and prepared for flow cytometry, Western blot, and qPCR analyses.

\section{TdT-mediated dUTP-biotin nick end labeling assay}

Tumor tissues away from the necrotic area were fixed in $4 \%$ formalin, paraffin-embedded and sectioned (thickness, $4 \mu \mathrm{m}$ ). The terminal deoxynucleotidyl transferase-mediated dUTP nick end labeling (TUNEL) apoptosis assay kit (Roche, IN USA) was used according to the manufacturer's protocol. The slides were observed under a fluorescence microscope (Olympus BX51T-PHD-J11, Tokyo, Japan). Counts of TUNEL positive nuclei were performed by counting the total number of stained nuclei across $400-\mu \mathrm{m}$ sections of each sample.

\section{Statistical analysis}

Data were analyzed using SPSS 17.0 (SPSS, Inc., IL, USA). All experiments were repeated in triplicate, and data were presented as the mean \pm standard deviation. One-way analysis of variance was used to compare two groups with normally distributed data, followed by a post-hoc Newman-Keuls test. A $P$ value $<0.05$ was considered to indicate a statistically significant difference.

\section{Results}

MAT induced the differentiation sensitivity recovery of NB4-LR1 cells to ATRA

The differentiation level was detected using flow cytometry (Fig. 1a) and NBT reduction assay (Fig. 1b). After treatment with the corresponding drugs for $72 \mathrm{~h}$, the expression level of CD11b was found to be increased in both cell lines except for the MAT group, compared with the control group $(P<0.01$ or $P<0.05)$. Also, the differentiation rate was significantly lower in NB4-LR1 cells than in NB4 cells. The NBT-positive rate did not increase in the ATRA + MG group. Compared with the ATRA group, ATRA + MAT showed further increased expression of CD11b in NB4-LR1 cells $(P<0.01)$ but not in NB4 cells; and ATRA + RAPA further promoted the positive expression of CD11b in both cell lines $(P<0.05)$, but not NBT-positive rate in NB4 cells. ATRA + STI could significantly promote the expression of CD11b $(P<0.05)$ in NB4-LR1 cells but not in NB4 cells. However, MG132 might suppress the expression $(P<0.01)$ in NB4 cells. Compared with the ATRA + MAT group, the ATRA + RAPA might exhibit a considerable effect in promoting the expression of CD11b and NBT, especially in NB4-LR1 cells $(P<0.01)$. However, ATRA + STI or ATRA + MG might have a lower effect on the induction of differentiation $(P<0.01$ or $P<0.05)$ in NB4-LR1 cells; the ATRA+MAT+MG and ATRA+MAT+HCQ group both had a significantly lower expression of CD11b and NBT-positive rate $(P<0.01)$.

MAT induced the degradation of PML-RAR $\alpha$ and increased the expression of PML $m R N A$

PML-RAR $\alpha$ is crucial in the genesis and progression of the disease [1]. The Western blot analysis was used for detecting the expression of PML-RAR $\alpha$ fusion protein (Fig. 1c, 1d, 1f, and $1 \mathrm{~g}$ ). The result showed that ATRA could decrease the expression of the PML-RAR $\alpha$ fusion protein in NB4 cells but not in NB4-LR1 cells. However, MAT alone did not have a significant effect on both cell lines. ATRA combined with MAT, RAPA, STI, or MG led to a significant decrease in the expression of fusion protein in NB4-LR1 cells but not in NB4 cells compared with ATRA-alone treatment. This phenomenon was distinctly observed with respect to MAT and RAPA $(P<0.01)$, and the combination effect of MAT could be reversed using HCQ $(P<$ 0.01 ) but not MG. The expression levels of PML-RAR $\alpha$ mRNA were in consistent with the change in the expression of fusion protein, MAT + MG could decrease the expression of fusion protein but not of the PML-RAR $\alpha$ mRNA (Fig. 1i). After the degradation of the fusion protein, PML was released and the APL cell regained the ability to differentiate [12]. The Western 


\section{Cellular Physiology Cell Physiol Biochem 2018;48:2286-2301

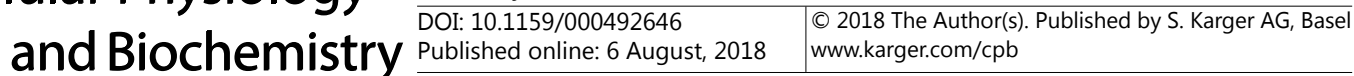 \\ Wu et al.: Mechanism of Matrine on Differentiation Recovery of ATRA-Resistant APL \\ Cells}

Fig. 1. MAT promotes the differentiation and induces the degradation of PML-RAR $\alpha$ protein in NB4-LR1 cells in vitro. NB4 and NB4-LR1 cells were treated respectively with solvent, ATRA (1 $\mu \mathrm{mol} / \mathrm{L})$, MAT ( $0.1 \mathrm{mmol} / \mathrm{L})$, ATRA combined with MAT, ATRA combined with Rapamycin $(100 \mathrm{nmol} / \mathrm{L}$, autophagy activator), ATRA combined with STI571 (5 $\mu \mathrm{mol} / \mathrm{L}, \mathrm{RAR} \alpha$ ubiquitin stabilizer), MG132 (1 $\mu \mathrm{mol} / \mathrm{L}$, proteasome inhibitor), ATRA combined with MG132,MAT combined with MG132, ATRA combined with MAT and MG132, ATRA combined with MAT and hydroxychloroquine (HCQ 16 $\mu \mathrm{mol} / \mathrm{L}$, autophagy inhibitor) for $72 \mathrm{~h}$. (a) Expression of CD11b. (b) Positive rate of NBT. (ch) Western-blot analysis of the PML-RAR $\alpha$ fusion protein and PML protein, and quantitation were analyzed using Image J 1.46r software. Relative aboundances of the proteins were expressed relative to $\beta$-actin, which was set at 1.00. (i) q-PCR analysis of PML-RAR $\alpha$ mRNA expression. Data are presented as mean $\pm \mathrm{SD} ;{ }^{*} \mathrm{P}<0.05$, and ${ }^{* *} \mathrm{P}<0.01$ (as compared with the control group); $+\mathrm{P}<0.05$, and $++\mathrm{P}<0.01$ (as compared with the ATRA treated group); $\# \mathrm{P}<0.05$, and $\# \# \mathrm{P}<0.01$ (as compared with the ATRA and MAT co-treated group); $\& \mathrm{P}<0.01$ (as compared with the MAT group).

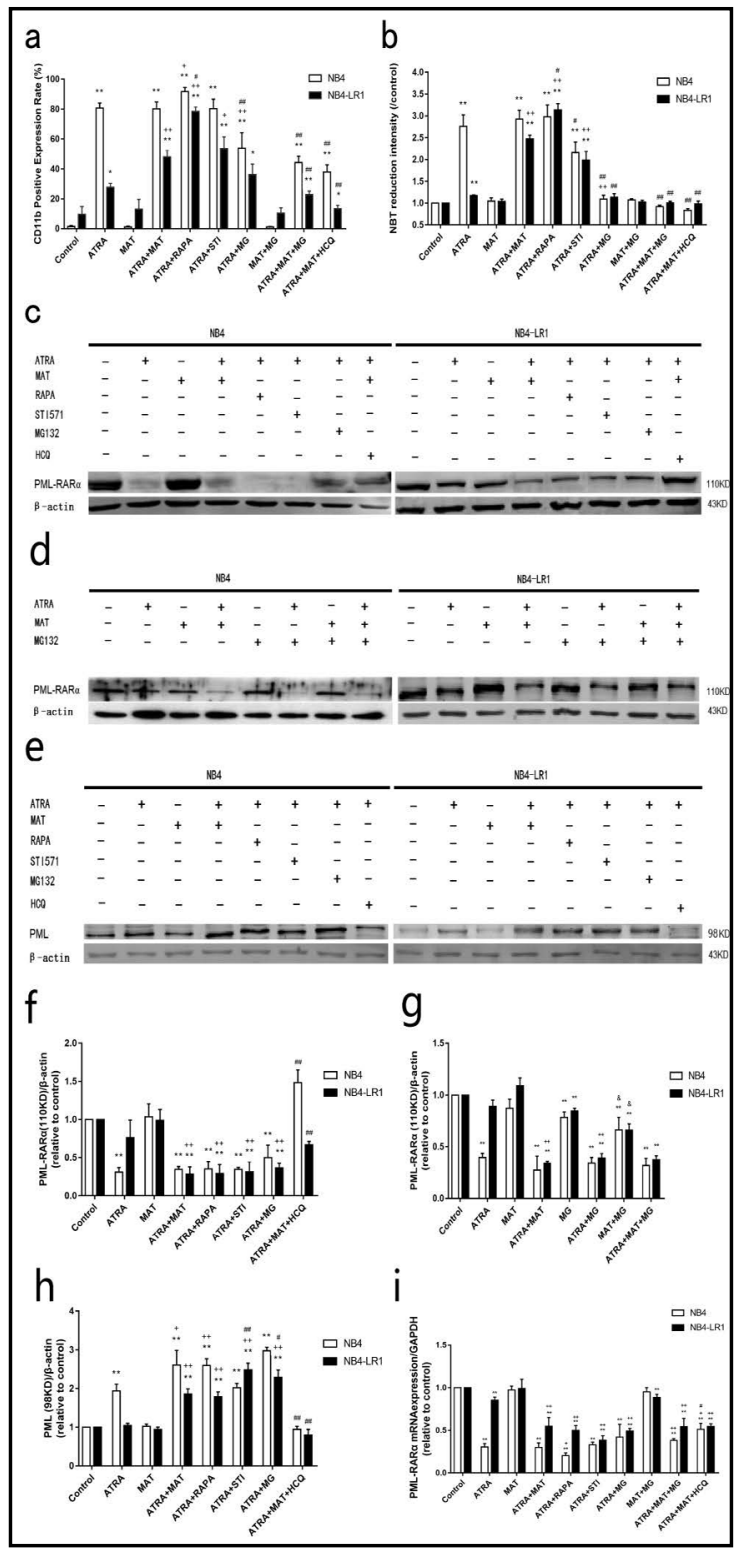

blot analysis results (Fig. 1e, and $1 \mathrm{~h}$ ) revealed that the expression of PML protein expression increased only in NB4 cells when treated with ATRA alone, but not with MAT. Besides ATRA combined with MAT, RAPA, STI, or MG132 could upregulate the expression of PML protein in both cell lines $(P<0.05)$, and the combination effect of MAT could be reversed by adding HCQ $(P<0.01)$.

\section{MAT upregulated the ubiquitylation level in NB4-LR1 cells}

The Western blot analysis detected the intensity of ubiquitylation level after treatment for $72 \mathrm{~h}$ (Fig. 2a). ATRA led to a decreased expression of ubiquitylation protein in both cell lines, whereas the effect could be reversed significantly in NB4-LR1 cells when replaced or co-treated with MAT. A similar phenomenon was not observed in NB4 cells. MG132 promoted the ubiquitylation protein level significantly in all treated groups, especially when co-treated with MAT. 
Fig. 2. MAT promotes the ubiquitylation in NB4-LR1 cells by stabilizes the $20 \mathrm{~S}$ protein expression and enhances the activity of proteasome. NB4 and NB4-LR1 cells were treated respectively with solvent, ATRA (1 $\mu \mathrm{mol} / \mathrm{L})$, MAT $(0.1 \mathrm{mmol} / \mathrm{L})$, ATRA combined with MAT, MG132 ( $1 \mu \mathrm{mol} / \mathrm{L})$, ATRA combined with MG132, MAT combined with MG132, ATRA combined with MAT and MG132 for $72 \mathrm{~h}$. (a) Westernblot analysis of the ubiquitylation level in NB4 and NB4-LR1 cells. (b-d) Western-blot analysis of the $20 \mathrm{~S}$ protein in both cells, and quantitation was analyzed using Image J 1.46r software. (e) Activity of proteasome detected by

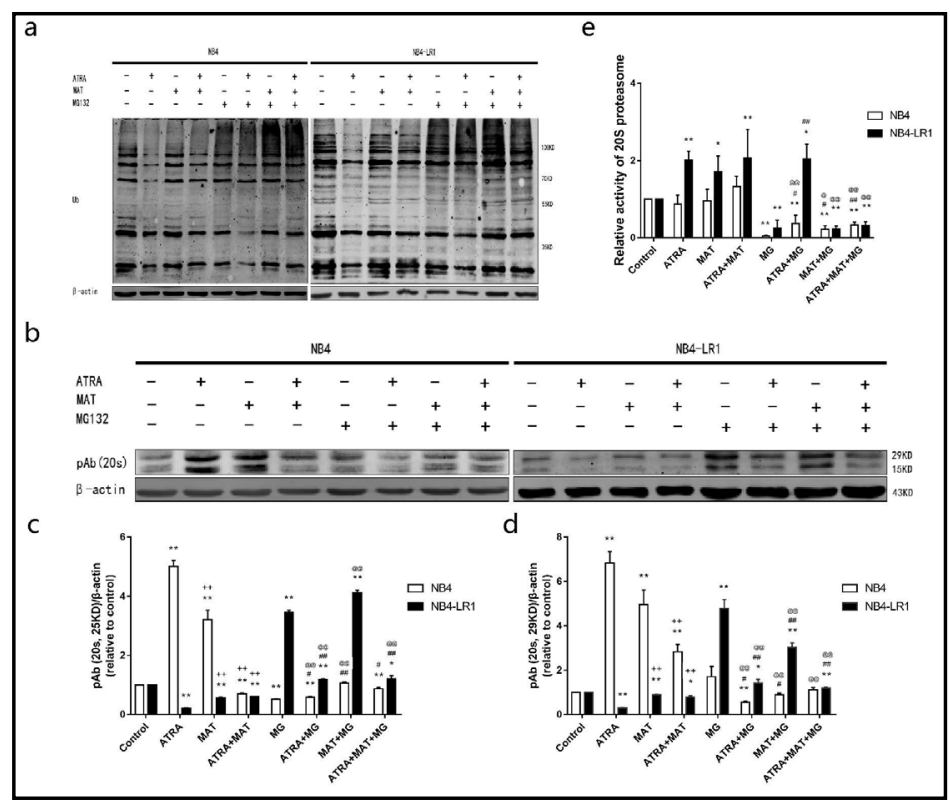
fluorescent substrate Suc-LLVY-AMC. Data are presented as mean $\pm \mathrm{SD}$; ${ }^{*} \mathrm{P}<0.05$, and ${ }^{* *} \mathrm{P}<0.01$ (as compared with the control group); $+\mathrm{P}<0.05$, and $++\mathrm{P}<0.01$ (as compared with the ATRA treated group); \# $<0.05$, and \#\#P<0.01 (as compared with the ATRA and MAT co-treated group); @P $<0.05$, and @@ $@<0.01 \mathrm{P}$ (as compared with MG132 treated group).

MAT stabilized the 20S protein expression and enhanced the activity of the proteasome

$20 \mathrm{~S}$ is vital in the activity of the proteasome. Therefore, the Western blot analysis was carried out to measure the protein expression of $20 \mathrm{~S}$ (Fig. 2b-2d). The results showed that the treatment with ATRA or MAT alone could enhance the expression of $20 \mathrm{~S}$ ( 29 and $25 \mathrm{kDa}$ ) in NB4 cells, whereas ATRA + MAT could only increase the level of 20S (29 kDa) compared with the control group. MG132 inhibited the expression of $20 \mathrm{~S}(29$ and $25 \mathrm{kDa})(P<0.01)$ which increased using ATRA or MAT in NB4 cells. However, a different phenomenon was observed in NB4-LR1 cells. ATRA resulted in a remarkable suppression of 20S expression $(P$ $<0.05)$ in NB4-LR1 cells, which could be restored using the combination of MAT $(P<0.01)$, and MG132 led to an increased expression of 20S (29 and 25 KD) in NB4-LR1 cells $(P<0.01)$.

In addition to the protein expression, the activity of the proteasome was also detected using fluorescent substrate Suc-LLVY-AMC (Fig. 2e). The treatment with ATRA, MAT, or ATRA + MAT did not significantly alter the 20S activity in NB4 cells. However, a remarkable upregulation was observed in NB4-LR1 cells compared with the control cells $(P<0.01$ or $P$ $<0.05)$. No differences were observed among the three treated groups. Co-treatment with MG132 inhibited the activity of 20S in all the treated groups of both cell lines $(P<0.01$ or $P$ $<0.05$ ) except the NB4-LR1 cells treated with ATRA. ATRA and MAT alone or together could reverse the inhibitory activity of MG132 on 20S in NB4 cells. No significant differences were observed in NB4-LR1 cells except for the ATRA + MG group, which showed a remarkable increase $(P<0.01)$.

\section{MAT stabilized the expression of RAR $\alpha$}

The expression level of RAR $\alpha$ was detected using the Western blot analysis (Fig. 3). The results showed that treatment with MAT alone increased the level of RAR $\alpha$ significantly in both cell lines $(P<0.01)$. ATRA also upregulated the expression of RAR $\alpha$ in NB4 cells $(P<$ $0.01)$, but the effect was lower than that of MAT $(P<0.01)$. ATRA inhibited the expression of RAR $\alpha$ in NB4-LR1 cells $(P<0.01)$. Furthermore, ATRA + MAT did not show a synergistic 


\section{Cellular Physiology Cell Physiol Biochem 2018;48:2286-2301

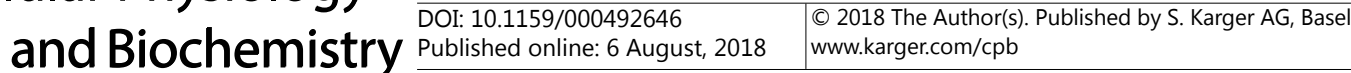 Wu et al.: Mechanism of Matrine on Differentiation Recovery of ATRA-Resistant APL Cells}

Fig. 3. MAT stabilizes the expression of RAR $\alpha$ in NB4-LR1 cells. NB4 and NB4-LR1 cells were treated respectively with solvent, ATRA $(1 \mu \mathrm{mol} / \mathrm{L})$, MAT (0.1 mmol/L), ATRA combined with MAT, MG132 (1 $\mu \mathrm{mol} / \mathrm{L})$, ATRA combined with MG132, MAT combined with MG132, ATRA combined with MAT and MG132 for $72 \mathrm{~h}$. Data are presented as mean $\pm \mathrm{SD} ;{ }^{*} \mathrm{P}<0.05$, and ${ }^{* *} \mathrm{P}<0.01$ (as compared with the control group); $+\mathrm{P}<0.05$, and $++\mathrm{P}<0.01$ (as compared with the ATRA treated group); \#P <

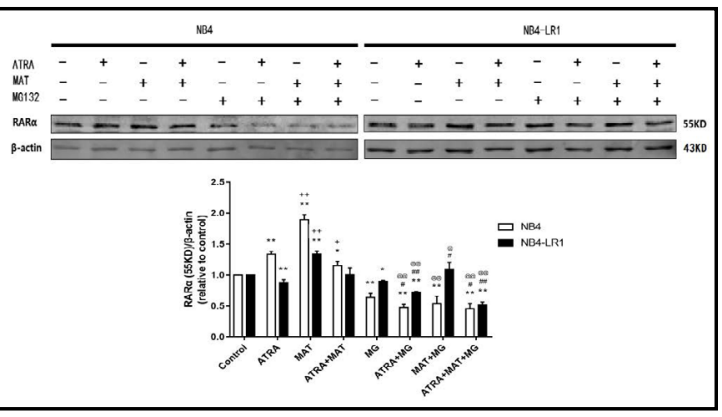
0.05 , and \#\#P<0.01 P (as compared with the ATRA and MAT co-treated group); @P $<0.05$, and @@P $<0.01 \mathrm{P}$ (as compared with MG132 treated group).

effect in both cells compared with the ATRA group. MG132 inhibited the expression of RAR $\alpha$ in both cell lines $(P<0.01$ or $P<0.05)$, and co-treatment with ATRA or ATRA+MAT strengthened the inhibitory effect $(P<0.01$ or $P<0.05)$.

\section{MAT promoted the process of autophagy}

Autophagy was observed under an electron microscope (Fig. 4a). ATRA-alone treatment induced autophagy in NB4 cells but not in NB4-LR1 cells, whereas MAT alone exerted an opposite effect. Co-treatment with ATRA and MAT increased the number of autophagosome in both cell lines significantly. RAPA enhanced the effect of ATRA-induced up-regulation of autophagy in both cell lines. However, the effect was lower when ATRA was coupled with MAT. STI571 induced the process of autophagy in both cell lines but not MG132.

Autophagy-related proteins were detected using the Western blot analysis to further explain the effect of MAT on autophagy induction (Fig. 4b-4e). LC3II is the marker protein of autophagy. The increase in LC3-II and LC3-II/LC3-I ratio, along with the exhaustion of P62 might indicate the activation of autophagy and the fluency of autophagy flux. The result showed that both ATRA and MAT significantly increased the LC3-II/LC3-I ratio $(P<0.01)$ in NB4 cells, along with the decreased expression of $\mathrm{P} 62(P<0.01$ or $P<0.01)$. However, the effect was much less in NB4-LR1 cells. No significant change in LC3-II/LC3-I ratio was observed in NB4-LR1 cells treated with ATRA, and the decrease in P62 was much minor. The combination of ATRA and MAT could further up-regulate the LC3-II/LC3-I ratio in NB4LR1 cells $(P<0.05)$, but not in NB4 cells. ATRA + MAT also decreased the expression of P62 further in both cells $(P<0.01)$. ATRA coupled with RAPA, STI, or MG132 reversed the LC3II/LC3-I ratio compared with the ATRA-alone treatment $(P<0.05$ or $P<0.01)$ in NB4 cells, although the P62 expression was also down-regulated in the ATRA + STI and ATRA + RAPA group $(P<0.01)$ and remained in the ATRA + MG132 group. However, in NB4-LR1 cells, the combination of ATRA with RAPA, STI, or MG132 increased the LC3-II/LC3-I ratio further compared with the ATRA group $(P<0.05$ or $P<0.01)$. The P62 protein decreased in the ATRA + RAPA, and ATRA + STI groups $(P<0.01)$ but increased in the ATRA + MG132 group $(P<0.01)$.

The expression of LC3 after the combination with lysosomal inhibitor, HCQ was detected to estimate the autophagic flux activity during ATRA + MAT treatment in NB4-LR1 cells (Fig. 4f). The result showed that the combination with HCQ significantly increased the expression level of LC3II in both NB4 and NB4-LR1 cells, and the change was more obvious in the ATRA + MAT + HCQ group than in the MAT + HCQ group.

The expression of autophagy-related proteins, Atg1, PI3KC3, and Atg5, was also detected using Western blot analysis (Fig. 4g-j). Treatment with ATRA and MAT, alone or together, increased the expression of Atg1 and PI3KC3 in NB4 cells $(P<0.01$ or $P<0.05)$, and ATRA with MAT, RAPA or STI571 could not further upregulate the expression of Atg1 and PI3KC3 compared with the ATRA alone. STI571 exerted an inhibitory effect on PI3KC3 and MG132 promoted the expression of PI3KC3 in NB4 cells. However, in NB4-LR1 cells, treatment with ATRA alone inhibited the expression of Atg1 and PI3KC3, and MAT alone also downregulate 
Fig. 4. MAT promotes the process of autophagy in NB4-LR1 cells. NB4 and NB4-LR1 cells were treated respectively with solvent, ATRA (1 $\mu \mathrm{mol} / \mathrm{L})$, MAT $(0.1 \mathrm{mmol} / \mathrm{L})$, ATRA combined with MAT, ATRA combined with Rapamycin (100nmol/L), ATRA combined with STI571 $(5 \mu \mathrm{mol} / \mathrm{L})$, ATRA combined with MG132 (1 $\mu \mathrm{mol} / \mathrm{L})$, and ATRA combined with MAT and HCQ $(16 \mu \mathrm{mol} / \mathrm{L})$ for $72 \mathrm{~h}$. (a) Observation of autophagosome in both cell lines by electron microscopic. (b, c) Western-blot analysis of the autophagy-related protein LC3, and quantitation (LC3II/LC3I) was analyzed using Image J 1.46r software. (d, e) Western-blot analysis of the P62, and quantitation was analyzed using Image J 1.46r software. (fj) Western-blot analysis of the autophagy-related protein Atg1, PI3KC3, and Atg5, and quantitation were analyzed using Image J 1.46r software. Data are presented as mean $\pm \mathrm{SD} ;{ }^{*} \mathrm{P}<0.05$, and ${ }^{* *} \mathrm{P}<0.01$ (as compared with the control group); $+\mathrm{P}<0.05$, and $++\mathrm{P}<0.01$ (as compared with the ATRA treated group).

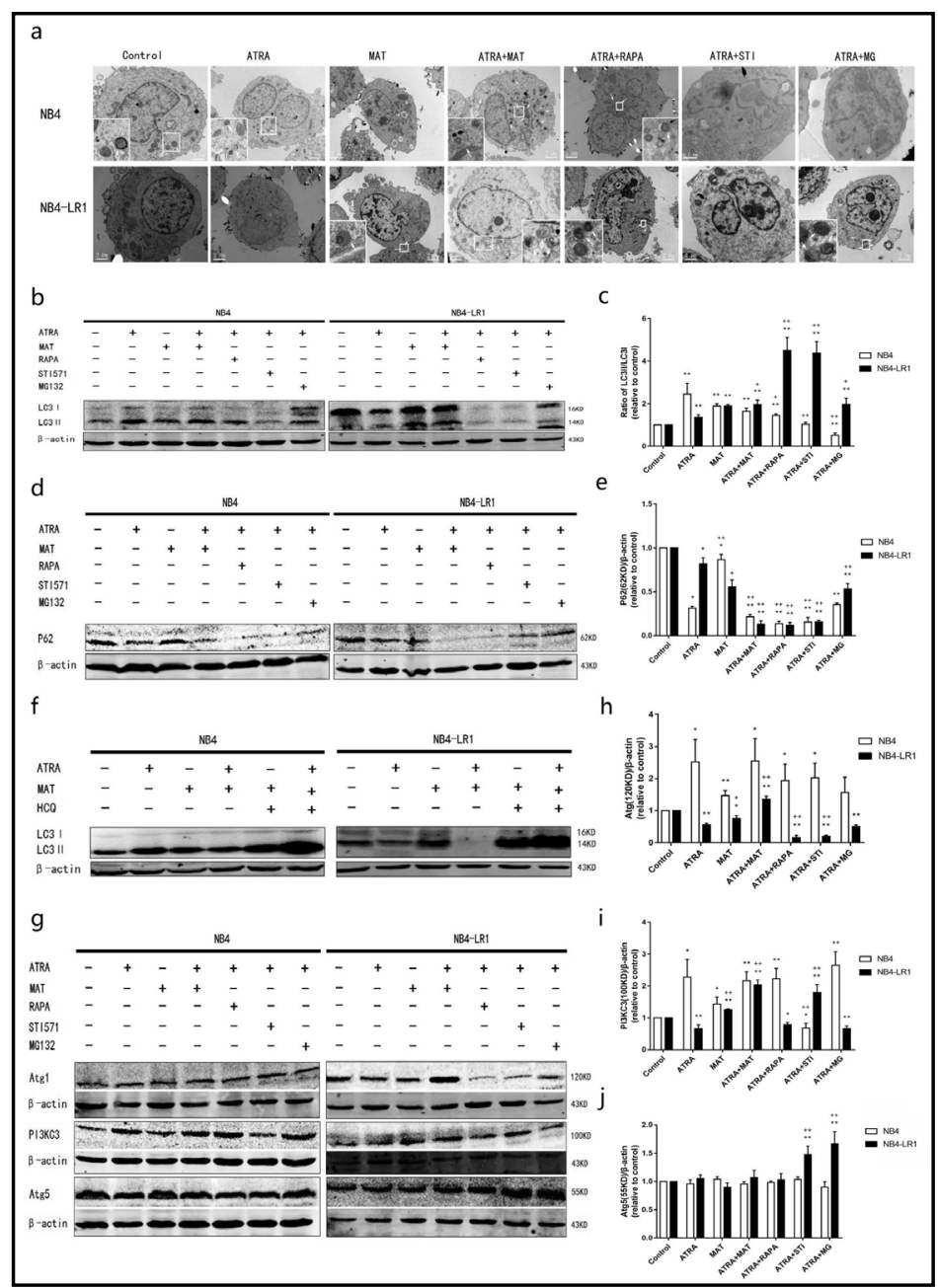

the expression of Atg1. This phenomenon was reversed significantly when the cells were treated with ATRA + MAT $(P<0.01)$. RAPA and STI571 further downregulated the expression of Atg1, and increased the expression of PI3KC3 in NB4-LR1 cells $(P<0.01)$. No significant changes were observed in expression of Atg5 in NB4 cells after treatments, and ATRA + STI571 or ATRA + MG132 increased the expression of Atg5 in NB4-LR1 cells compared with the ATRA-alone treatment.

\section{MAT induced the differentiation of xenograft tumor cells and apoptosis in nude mice}

A subcutaneous xenograft mouse model using NB4 and NB4-LR1 cells was employed to determine whether MAT exerted an in vivo effect similar to that in vitro. The treatment with ATRA alone did not reduce the size of tumor in ATRA-sensitive NB4 xenograft mouse. The combination treatment even enlarged the tumor (Fig. 5a), which was in accordance with the clinical manifestation of patients with APL who received ATRA alone as chemotherapy. Unlike the cytotoxic drugs, ATRA induces the differentiation of APL, followed by an explosive multiplication of differentiated myelocytes [13]. In NB4-LR1 xenograft mouse, the combination treatment group also had a larger size of tumors compared with the control group. However significant necrosis and apoptosis were observed in the group, and NB4LR1 xenograft mouse model (Fig. 5b).

Flow cytometry revealed a marked increase in the expression of CD11b and a significant decrease in the expression of PML-RAR $\alpha$ fusion gene in NB4-LR1 xenograft tumor tissue in the co-treated group, similar to that in the in vitro study (Fig. 5c, and 5d). Apoptosis occurred 


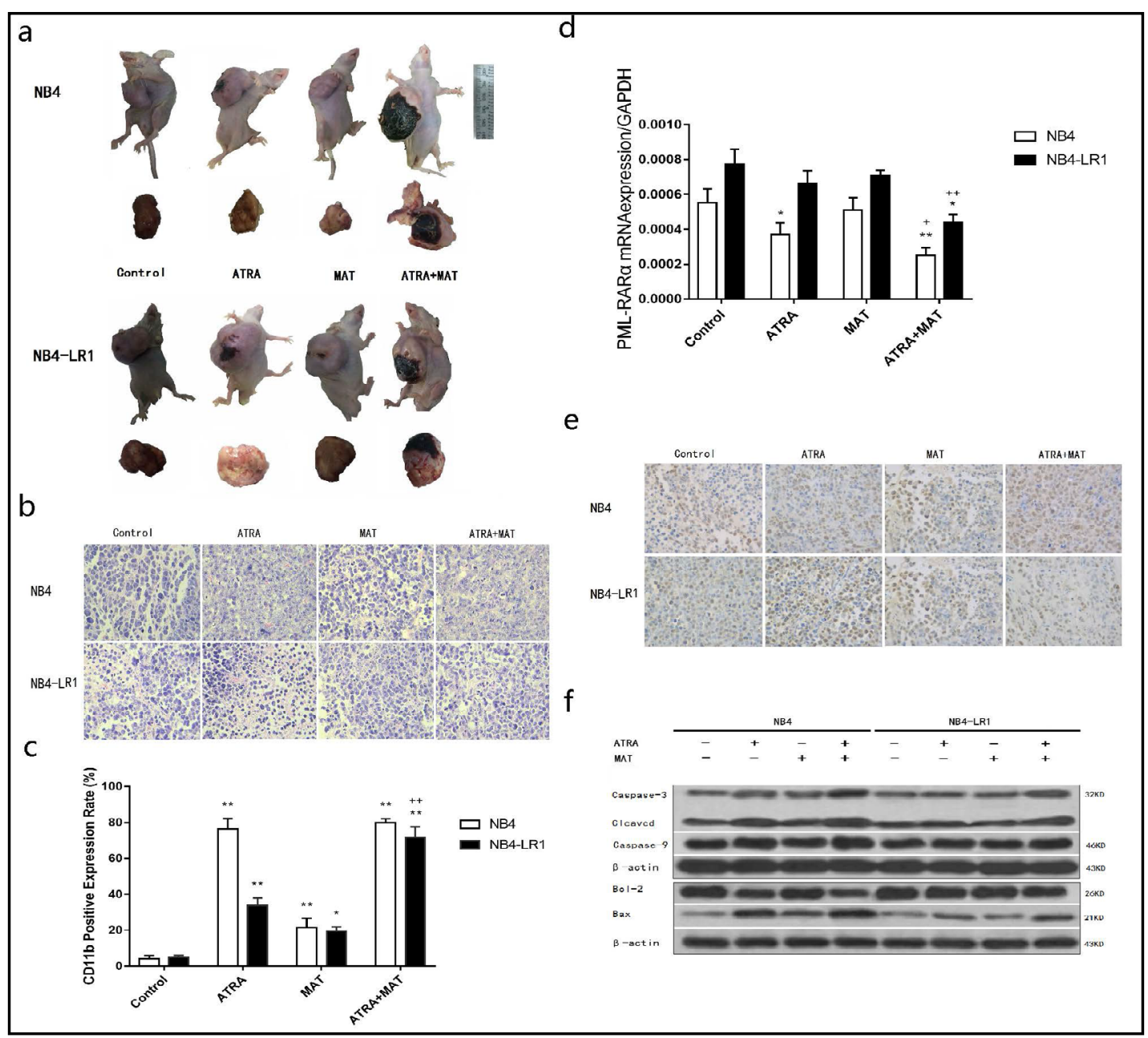

Fig. 5. MAT induces the differentiation of xenograft tumor cells as well as apoptosis in vivo. Mice were randomized divided into four groups. After tumor bearing, all mice were administrated with $0.9 \%$ normal saline, $25 \mathrm{mg} / \mathrm{kg}$ body weight of ATRA, 38mg / $\mathrm{kg}$ body weight of MAT, ATRA combined with MAT intraperitoneally daily for 3weeks, respectively. (a) General observation of the xenograft tumor in nude mice. (b) Morphological observation under light microscope after HE stain. (c) CD11b expression with flow cytometry. (d) Apoptosis rate detected by TUNEL. (e) Western-blot analysis of the apoptosis related protein. (f) Expression of PML-RAR $\alpha$ fusion mRNA. Data are presented as mean $\pm \mathrm{SD}$; ${ }^{*} \mathrm{P}<0.05$, and ${ }^{* *} \mathrm{P}<0.01$ (as compared with the control group); $+\mathrm{P}<0.05$, and $++\mathrm{P}<0.01$ (as compared with the ATRA treated group).

before necrosis. The TUNEL assay and Western blot analysis were used to detect the apoptosis in the groups. The results showed that in NB4 cells, ATRA alone could significantly improve the TUNEL-positive rate $(61.4 \% \pm 5.59 \%$ vs $36.0 \% \pm 9.05 \%, P<0.01)$, whereas MAT alone did not show a significant effect $(52.3 \% \pm 12.69 \%)$. The ATRA+MAT treatment led to a markedly increased expression $(68.67 \% \pm 11.71 \%, P<0.01)$ compared with the control group. No obvious differences were observed compared with the ATRA group. In the NB4LR1 cells, no distinct effects were observed when treated with ATRA or MAT alone $(47.67 \%$ $\pm 23.46 \%$ and $39.5 \% \pm 2.12 \%$ respectively) compared with the control group $(39.5 \%$ $\pm 9.47 \%$ ). However, after co-treatment with ATRA and MAT, the expression level further increased to $64.4 \% \pm 10.76 \%$; the differences were not significant compared with the ATRA group (Fig. 5e). The Western blot analysis showed the increased expression of caspase- 3 in NB4 cells treated with ATRA or MAT alone but not in NB4-LR1 cells; the combination treatment upregulate the expression further. No significant change was observed in the expression of caspase-9 in all groups. ATRA-alone treatment downregulate the expression of 


\section{Cellular Physiology

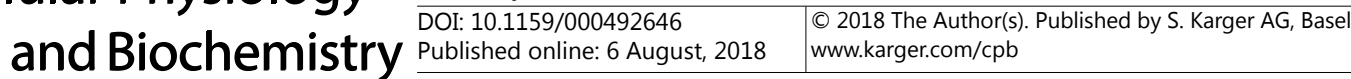 \\ Wu et al.: Mechanism of Matrine on Differentiation Recovery of ATRA-Resistant APL \\ Cells}

Bcl-2 in NB4 cells, but not in NB4-LR1cells. MAT alone did not affect the expression of Bcl-2in both cell lines. An opposite effect was noted in the expression of Bax. An increased expression was observed in NB4-LR1 cells treated with ATRA, which was much lower than that in NB4 cells. The expression increased further with the combination treatment in both cell lines (Fig. 5f).

Furthermore, the Western blot analysis detected the autophagy and ubiquitination processes. qPCR evaluated the proliferation/ differentiation of the genes. At the protein level, ATRA or MAT alone upregulated the expression of autophagyrelated proteins (LC3, ATG5, ATG1, and PI3KC3), ubiquitin-related proteins (UB, 20S, RAR $\alpha F$ and TRIM32), and proliferation-

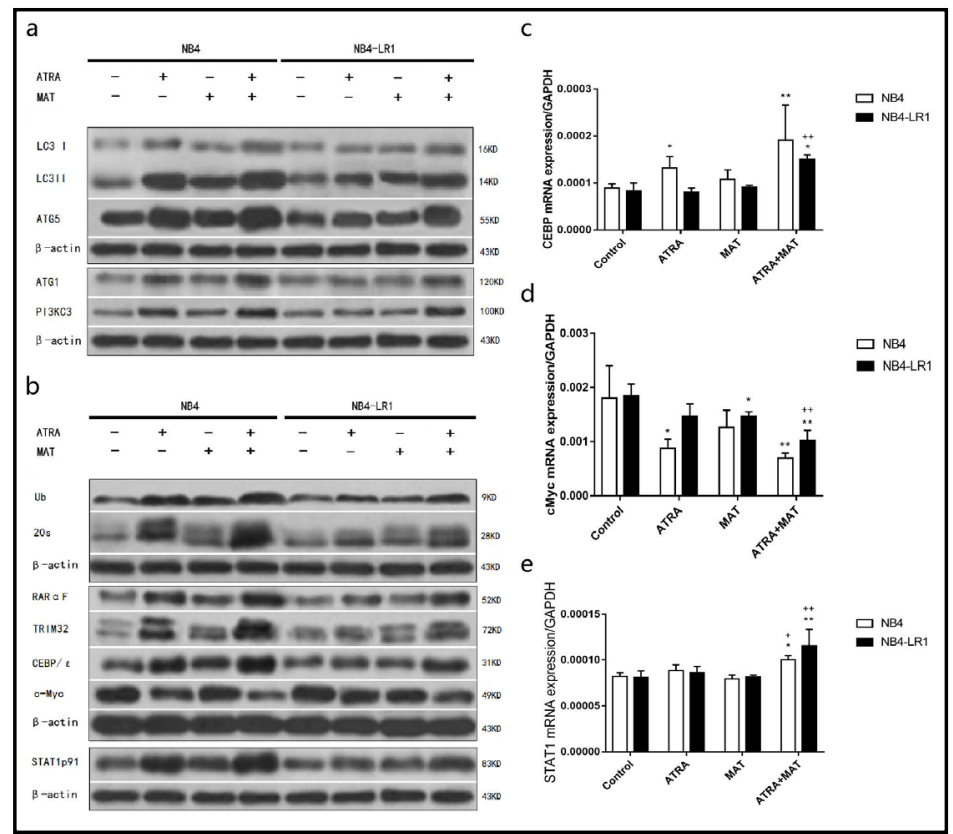

Fig. 6. MAT promotes the ubiquitination and autophagy process and increase the expression of proliferation/differentiation related protein/gene in vivo. (a) Western-blot analysis of the autophagy related protein. (b) Western-blot analysis of the ubiquitin-proteasome and related proliferation/differentiation protein. (c-e) Expression of proliferation/differentiation related gene CEBP, c-Myc, and STAT1. Data are presented as mean $\pm \mathrm{SD}$; $\mathrm{P}<0.05$, and ${ }^{* *} \mathrm{P}<0.01$ (as compared with the control group); $+\mathrm{P}<0.05$, and $++\mathrm{P}<0.01$ (as compared with the ATRA treated group). related protein $(\mathrm{C} / \mathrm{EBP} \varepsilon$

and STAT1p91) in NB4 cells. ATRA decreased the expression of c-Myc compared with the control. The effect of ATRA was more than that of MAT, and the combination of ATRA and MAT was rather effective. In NB4-LR1 cells, the same single treatment could only increase the expression of LC3 and ATG5, and did not affect the expression of ATG1 and PI3KC3 compared with the control. The combination treatment led to a markedly increased expression of LC3, ATG5, ATG1, and PI3KC3 (Fig. 6a). ATRA but not MAT alone increased the expression of Ub, 20S, RAR $\alpha$ F, TRIM32, C/EBPE, and STAT1p91; however, it was lower than that in NB4 cells. The combination treatment significantly upregulated the expression of UB, 20S, RAR $\alpha$ F, TRIM32, C/EBPE, and STAT1p91 and inhibited the expression of c-Myc (Fig. 6b). At the mRNA level, ATRA increased the expression of C/EBP $\varepsilon$ and inhibited the expression of c-Myc in NB4 cells $(P<0.05)$ but not in NB4-LR1 cells. However, MAT could decrease the expression of c-Myc mRNA in NB4-LR1 cells $(P<0.05)$ compared with the control. The combination treatment promoted the expressions of STAT1 and C/EBP $\varepsilon$ and inhibited that of c-Myc in NB4-LR1 cells $(P<0.05$ or $P<0.01$ ) (Fig. 6c-6e).

\section{Discussion}

In APL, the generation of PML-RAR $\alpha$ fusion protein inhibits the PML-induced transcription and the function of wild RAR $\alpha$, impairing the process of differentiation and maturation of myeloid cells. The most efficient agents, ATRA and ATO, both directly target PML/RAR $\alpha$-mediated transcriptional repression and protein stability [14], contributing to a significant decrease in the expression level of fusion protein. The induction of autophagy is a key component of ATRA-induced differentiation in APL, and during the treatment of ATRA 


\section{Cellular Physiology Cell Physiol Biochem 2018;48:2286-2301 \\ \begin{tabular}{l|l} 
DOI: 10.1159/000492646 & and Biochemistry \\
Published online: 6 August, 2018 & $\begin{array}{l}\text { O 2018 The Author(s). Published by S. Karger AG, Basel } \\
\text { www.karger.com/cpb }\end{array}$
\end{tabular} \\ Wu et al.: Mechanism of Matrine on Differentiation Recovery of ATRA-Resistant APL \\ Cells}

[15], the UPP is also activated [16]. The mechanism of ATRA resistance in APL is still not fully clarified. Whether and how autophagy and UPP are involved in ATRA resistance in APL needs to be explored. Previous studies demonstrated that a low cytotoxic dose of MAT could induce the response of ATRA-resistant APL cell to ATRA, and lead to the degradation of PMLRAR $\alpha$ fusion protein. The present study tried to clarify the possible mechanism underlying ATRA resistance and how MAT functioned based on the ubiquitin- and autophagy-mediated target protein degradation.

The UPP mainly consists of ubiquitin (Ub), ubiquitin-activating enzyme (E1), ubiquitin-conjugating enzymes (E2), ubiquitin protein ligases (E3), 26S proteasome, and deubiquitinating enzymes. The target protein firstly processes the attachment of ubiquitin with the help of E1, E2, and E3, and is finally recognized by the $26 \mathrm{~S}$ proteasome, which mediates protein degradation. $26 \mathrm{~S}$ is a multi-catalytic enzyme complex containing a $20 \mathrm{~S}$ catalytic core and two 19S regulatory complexes [17]. UPP was activated upon ATRA treatment in the human acute myeloid leukemia cell lines, NB4 and HL-60, with the up-regulated expression of ubiquitin mRNA and increased 20S proteasome activity [16]. The ubiquitinated proteins were further degraded, and the $20 \mathrm{~S}$ activity decreased with longer ATRA exposure [16]. The present study showed that the differentiation rate of NB4-LR1 cells in response to ATRA was much lower than that of NB4 cells, and the combination of MAT to ATRA restored the differentiation of NB4-LR1 cells, along with the decrease in the expression of PML-RAR $\alpha$ fusion protein/mRNA and upregulated expression of PML protein. The expression of 20S core subunit in NB4 cells increased significantly with ATRA treatment, but decreased in NB4LR1 cells, which could be revered with MAT. In fact, MAT could even increase the 20S activity in NB4-LR1 cells. It meant that ATRA + MAT exerted a differentiation-inducing effect via UPP activation. However, if the UPP activation was the only effect of MAT, the ubiquitylation protein level should be less than that in the ATRA group. Based on this, it was deduced that the ATRA + MAT also promoted the ubiquitylation process, facilitating the fusion protein degradation.

Further, proteasome inhibitor MG132 was used as the control. ATRA + MG enhanced the sensitivity of NB4-LR1 cells to ATRA, but exerted an inhibitory effect on NB4 cells. The combination of MG132 significantly increased the ubiquitylation level in both cells by downregulating proteasome activity, as reported earlier [18], and also induced the suppression of $20 \mathrm{~S}$ core subunit protein in NB4 cells. Although MG132 hampered the expression of cell differentiation marker (CD11b), the combination of MG132 did not exert a noticeable blocking effect on fusion protein degradation. It could even promote the process on MAT or ATRA treatment. It meant that some other pathways led to the degradation of fusion protein on MAT or MG132 treatment.

At present, the application of proteasome inhibitor in APL treatment and the underlying mechanism are still controversial. Reportedly, the proteasome inhibitor may cause excessive accumulation of PML-RAR $\alpha$-augmented endoplasmic reticulum stress, leading to APL-NB4 cell death [19], and also enhance the differentiation effect by RAR $\alpha$ stabilization and STAT1 activation [20]. To explain the inconsistency in the expression of fusion protein and cell differentiation on MG132 treatment, the RAR $\alpha$ expression was measured in different groups. ATRA facilitated the differentiation of APL cells into mature granulocytes by changing epigenetic modifiers on target genes after binding to the ligandbinding domain at the RAR $\alpha$ moiety of the PML-RAR [21]. Hence, the stabilization of RAR $\alpha$ is of great importance to the expression of downstream differentiation gene/protein. The results revealed that ATRA inhibited the expression of RAR $\alpha$ in NB4-LR1 cells, which was contradictory to that in NB4 cells. MAT stabilized the expression of RAR $\alpha$ in NB4-LR1 cells, whereas MG132 downregulated the expression of RAR $\alpha$ in both cell lines. The application of STI571 (a tyrosine kinase inhibitor, which exerted an effect on RAR $\alpha$ stabilization [22]) as a positive control further confirm that the RAR $\alpha$ stabilization effect of MAT benefited the differentiation of NB4-LR1 cells. The RAR $\alpha$ stabilization increased the expression of CD11b in NB4-LR1 cells to $53.52 \%$ and led to the degradation of fusion protein. 


\section{Cellular Physiology Cell Physiol Biochem 2018;48:2286-2301 and Biochemistry Published online: 6 August, $2018 \quad \begin{aligned} & \text { DOI: 10.1159/000492646 } 2018 \text { The Author(s). Published by S. Karger AG, Basel } \\ & \text { www.karger.com/cpb }\end{aligned}$ Wu et al.: Mechanism of Matrine on Differentiation Recovery of ATRA-Resistant APL Cells}

In addition to UPP, the autophagy pathway also had a significant role in arsenious acid- or ATRA-mediated PML-RAR $\alpha$ fusion protein degradation [23]. Autophagy is increased during ATRA-induced granulocytic differentiation of NB4 and it is associated with the increased expression of LC3II and GATE-16 proteins involved in autophagosome formation. Autophagy inhibition, using either drugs or short-hairpin RNA targeting the essential autophagy gene ATG7, attenuated myeloid differentiation [15]. The inhibition of autophagy-related genes such as Atg1, Atg5, and PI3KC3 and the knockdown of p62/SQSTM1 also blocked the degradation of PML-RAR $\alpha$ [24]. IThis study found that the combination with autophagy activator (rapamycin) significantly increased the cell differentiation of NB4-LR1 along with the decreased expression of PML-RAR $\alpha$ protein, which could be reversed by autophagy inhibitor (hydroxychloroquine). Moreover, autophagic degradation was not independent of UPP. Rather, the two pathways were closely correlated. After ubiquitination, the target protein was transported to autolysosome by P62, which was an autophagy receptor, interacted with autophagy-related protein LC3 [25], and finally degraded through autophagy [24].

The results showed that ATRA could not induce autophagy in NB4-LR1 cells, whereas the combination of MAT, rapamycin, STI571 or MG132 increased the number of autophagosomes. The induction of autophagy by STI571 might also be ascribed to its RAR $\alpha$-stabilization effect, which facilitated the effect of ATRA on NB4-LR1 cells. It also increased the expression of Atg5. LC3-II is the marker protein of autophagy. The increase in LC3-II and LC3-II/LC3-I ratio, along with the exhaustion of P62, might indicate the activation of autophagy and the fluency of autophagy flux [26]. Interestingly, ATRA impaired the process of autophagy with a decreased expression of LC3 II , Atg1, and PI3KC3 in NB4-LR1 cells, and the LC3-II/LC3-I ratio was much lower than that in NB4 cells. All these could be reversed by the ATRA + MAT or ATRA + RAPA treatment. After the combination with lysosomal inhibitors, a significantly increased expression of LC3II was observed in the MAT and ATRA + MAT groups, indicating the autophagy-activating effect of MAT. However, in NB4 cells, ATRA combined with MAT, RAPA, or STI571 negatively regulated the LC3II/LC3I ratio, and did not increase the expression of Atg1 and PI3KC3. These phenomena might explain the vain synergistic effect of NB4 cells treated with ATRA, STI571, and MG132. The increased LC3II/LC3I ratio and Atg5 expression, along with the decreased P62 expression in the ATRA+MG group compared with the ATRA group, indicated that MG132 also induced autophagy in NB4-LR1 cells, which might explain the decreased expression of fusion protein in ATRA + MG132, and MAT + MG132 groups.

The APL xenograft experiment was designed and a clinical application dose of ATRA and MAT was selected for the treatment to confirm that MAT also exerted an effect in vivo. As expected, ATRA coupled with MAT also exerted a significant effect in inducing the differentiation of NB4-LR1 cells compared with that in vitro (71.618 vs $48.02 \%$ ); also, the expression level of PML-RAR $\alpha$ mRNA decreased. In addition to differentiation, apoptosis and necrosis were observed. TUNEL detection showed an average increase of $7.27 \%$ and $16.73 \%$ in the combination group of NB4 and NB4-LR1, respectively. This phenomenon might be ascribed to the upregulated expression of caspase- 3 and Bax and the down-regulation of Bcl2 in the combination group, along with the suppression of c-Myc [27]. Also, a similar change in autophagy and UPP was found in vivo; the combination of ATRA and MAT improved the activity of UPP and autophagy pathway. Ubiquitin-protein ligase E (TRIM32) is vital in the UPP pathway, which interacts with several important proteins, including RAR $\alpha$, to stabilize the expression of RAR $\alpha$ and enhance the transcriptional activity of RAR $\alpha$. The overexpression of TRIM32 in HL60 cells induced granulocytic differentiation even in the absence of ATRA [28]. The stabilization of RAR $\alpha$ could further promote the downstream transcription factors, such as C/EBPE and STAT1p91 [29, 30]. The induction and activation of STAT1 correlated directly with enhanced cytodifferentiation [31]. The in vivo results showed a significant increase in TRIM32 in the MAT and ATRA + MAT groups, which was consistent with the expression of RAR $\alpha$, along with a higher expression of C/EBP $\varepsilon$ and STAT1p91. 


\section{Cellular Physiology Cell Physiol Biochem 2018;48:2286-2301 and Biochemistry Published online: 6 August, $2018 \quad \begin{aligned} & \text { DOI 10159/2018 The Author(s). Published by S. Karger AG, Basel } \\ & \text { www.karger.com/cpb }\end{aligned}$ Wu et al.: Mechanism of Matrine on Differentiation Recovery of ATRA-Resistant APL Cells}

\section{Conclusion}

The present study revealed the difference in the chain reaction of sensitive and resistant APL cell lines (NB4 and NB4-LR1, respectively) to the treatment of ATRA, explaining the mechanism underlying the resistance to ATRA. ATRA decrease the level of 20S core subunit and the RAR $\alpha$ in NB4-LR1 cells, but could not activate the autophagy process. These effects were reversed by the combination of MAT. The proteasome inhibitor might hamper the RAR $\alpha$ stabilization and hence was not advantageous for the differentiation of cells. It also induced autophagy in NB4-LR1 cells. MAT induced the activation of UPP and mediated the autophagic degradation process, which synergistically induced the degradation of PMLRAR $\alpha$ fusion protein and promote the differentiation of NB4-LR1 cells.

\section{Acknowledgements}

This study was supported by National Natural Science Foundation of China (NO. 81603573), Natural Science Foundation of Zhejiang Province (NO. LY14H290001, LY17H290005, Y2101416, LY17H290005), Scientific Research Fund of Zhejiang Provincial Education Department (NO.Y201223638), Zhejiang Outstanding Young Talent Fund of Traditional Chinese Medicine (N0.2013ZQ012) and Research Project for Practice Development of National TCM Clinical Research Bases (NO. JDZX2015116).

We cordially thank Professor Sun Jie and Huang He, from the Department of Bone marrow transplantation, Frist affiliated Hospital of Zhejiang University, for help and advice in this study.

Conception and design: Dijiong Wu, Keding Shao, Jie Sun, Baodong Ye, Yuhong Zhou. Development of methodology: Dijiong Wu, Qihao Zhou, Ziqi Wang, Fei Yan, Tingting Liu, Xiangping Wu. Acquisition of data: Qihao Zhou, Ziqi Wang, Fei Yan, Tingting Liu. Analysis and interpretation of data: Dijiong Wu, Qihao Zhou, Ziqi Wang, Fei Yan, Tingting Liu. Writing, review, and/or revision of the manuscript: Dijiong Wu, Baodong Ye.

This study was approved by the ethical committee of First Affiliated Hospital of Zhejiang Chinese Medical University on December 24, 2012 (NO. 2012-K-022-01).

\section{Disclosure Statement}

All authors declare that they have no competing interests.

\section{References}

1 Puccetti E, Ruthardt M: Acute promyelocytic leukemia: PML/RARalpha and the leukemic stem cell. Leukemia 2004;18:1169-1175.

-2 Pei R, Cao J, Ma J, Zhang P, Liu X, Du X, Chen D, Sha K, Chen L, Li S, Wu J, Fan Z, Lin L, Ye P, Tang S, Zhang $\mathrm{B}$ : Long term curative effects of sequential therapy with all-trans retinoic acid, arsenious oxide and chemotherapy on patients with acute promyelocytic leukemia. Hematology 2012;17:311-316.

-3 Ades L, Chevret S, Raffoux E, Guerci-Bresler A, Pigneux A, Vey N, Lamy T, Huguet F, Vekhoff A, Lambert JF, Lioure B, de Botton S, Deconinck E, Ferrant A, Thomas X, Quesnel B, Cassinat B, Chomienne C, Dombret H, Degos L, et al.: Long-term follow-up of European APL 2000 trial, evaluating the role of cytarabine combined with ATRA and Daunorubicin in the treatment of nonelderly APL patients. Am J Hematol 2013;88:556-559.

4 Ades L, Guerci A, Raffoux E, Sanz M, Chevallier P, Lapusan S, Recher C, Thomas X, Rayon C, Castaigne S, Tournilhac O, de Botton S, Ifrah N, Cahn JY, Solary E, Gardin C, Fegeux N, Bordessoule D, Ferrant A, MeyerMonard S, et al.: Very long-term outcome of acute promyelocytic leukemia after treatment with all-trans retinoic acid and chemotherapy: the European APL Group experience. Blood 2010;115:1690-1696. 


\section{Cellular Physiology Cell Physiol Biochem 2018;48:2286-2301 \begin{tabular}{l|l} 
DOI: 10.1159/000492646 & $\begin{array}{l}\text { O 2018 The Author(s). Published by S. Karger AG, Basel } \\
\text { www.karger.com/cpb }\end{array}$ \\
\hline
\end{tabular} \\ Wu et al.: Mechanism of Matrine on Differentiation Recovery of ATRA-Resistant APL \\ Cells}

-5 He P, Liu Y, Zhang M, Wang X, Xi J, Wu D, Li J, Cao Y: Interferon-gamma enhances promyelocytic leukemia protein expression in acute promyelocytic cells and cooperates with all-trans-retinoic acid to induce maturation of NB4 and NB4-R1 cells. Exp Ther Med 2012;3:776-780.

6 Xu DR, Huang S, Long ZJ, Chen JJ, Zou ZZ, Li J, Lin DJ, Liu Q: Inhibition of mitotic kinase Aurora suppresses Akt-1 activation and induces apoptotic cell death in all-trans retinoid acid-resistant acute promyelocytic leukemia cells. J Transl Med 2011;9:74.

7 Long Y, Lin XT, Zeng KL, Zhang L: Efficacy of intramuscular matrine in the treatment of chronic hepatitis B. Hepatobiliary Pancreat Dis Int 2004;3:69-72.

-8 Zhang S, Zhang Y, Zhuang Y, Wang J, Ye J, Zhang S, Wu J, Yu K, Han Y: Matrine induces apoptosis in human acute myeloid leukemia cells via the mitochondrial pathway and Akt inactivation. PLoS One 2012;7:e46853.

-9 Lu X, Zhu Z, Jiang L, Sun X, Jia Z, Qian S, Li J, Ma L: Matrine increases NKG2D ligand ULBP2 in K562 cells via inhibiting JAK/STAT3 pathway: a potential mechanism underlying the immunotherapy of matrine in leukemia. Am J Transl Res 2015;7:1838-1849.

10 Wu D, Shao K, Sun J, Zhu F, Ye B, Liu T, Shen Y, Huang H, Zhou Y: Matrine cooperates with all-trans retinoic acid on differentiation induction of all-trans retinoic acid-resistant acute promyelocytic leukemia cells (NB4-LR1): possible mechanisms. Planta Med 2014;80:399-408.

11 Wu DJ, Zhou YH, Zhu J, Zhao W, Zhong WJ, Wang Z, Qian H, Li R, Fu S, Sun J: [Study on matrine alleviating retinoic acid resistance in acute promyelocytic leukemia]. Zhonghua Xue Ye Xue Za Zhi 2011;32:313-316.

12 Baranger L, Gardembas M, Hillion J, Foussard C, Ifrah N, Boasson M, Berger R: Rearrangements of the RARA and PML genes in a cytogenetic variant of acute promyelocytic leukemia. Genes Chromosomes Cancer 1993;6:118-120.

13 Asou N, Fujita H, Shinagawa K: JSH guideline for tumors of hematopoietic and lymphoid tissues: leukemia: 2. Acute promyelocytic leukemia (APL). Int J Hematol 2017;106:459-470.

-14 Nasr R, Lallemand-Breitenbach V, Zhu J, Guillemin MC, de The H: Therapy-induced PML/RARA proteolysis and acute promyelocytic leukemia cure. Clin Cancer Res 2009;15:6321-6326.

15 Orfali N, O’Donovan TR, Nyhan MJ, Britschgi A, Tschan MP, Cahill MR, Mongan NP, Gudas LJ, McKenna SL: Induction of autophagy is a key component of all-trans-retinoic acid-induced differentiation in leukemia cells and a potential target for pharmacologic modulation. Exp Hematol 2015;43:781-793.e2.

16 Fang Y, Zhou X, Lin M, Jing H, Zhong L, Ying M, Luo P, Yang B, He Q: The ubiquitin-proteasome pathway plays essential roles in ATRA-induced leukemia cells G0/G1 phase arrest and transition into granulocytic differentiation. Cancer Biol Ther 2010;10:1157-1167.

17 Tu Y, Chen C, Pan J, Xu J, Zhou ZG, Wang CY: The Ubiquitin Proteasome Pathway (UPP) in the regulation of cell cycle control and DNA damage repair and its implication in tumorigenesis. Int J Clin Exp Pathol 2012;5:726-738.

18 Alexandrova A, Petrov L, Georgieva A, Kessiova M, Tzvetanova E, Kirkova M, Kukan M: Effect of MG132 on proteasome activity and prooxidant/antioxidant status of rat liver subjected to ischemia/reperfusion injury. Hepatol Res 2008;38:393-401.

19 Takenokuchi M, Miyamoto K, Saigo K, Taniguchi T: Bortezomib Causes ER Stress-related Death of Acute Promyelocytic Leukemia Cells Through Excessive Accumulation of PML-RARA. Anticancer Res 2015;35:3307-3316.

20 Ying M, Zhou X, Zhong L, Lin N, Jing H, Luo P, Yang X, Song H, Yang B, He Q: Bortezomib sensitizes human acute myeloid leukemia cells to all-trans-retinoic acid-induced differentiation by modifying the RARalpha/ STAT1 axis. Mol Cancer Ther 2013;12:195-206.

21 Nitto T, Sawaki K: Molecular mechanisms of the antileukemia activities of retinoid and arsenic. J Pharmacol Sci 2014;126:179-185.

22 Gianni M, Kalac Y, Ponzanelli I, Rambaldi A, Terao M, Garattini E: Tyrosine kinase inhibitor STI571 potentiates the pharmacologic activity of retinoic acid in acute promyelocytic leukemia cells: effects on the degradation of RARalpha and PML-RARalpha. Blood 2001;97:3234-3243.

-23 Isakson P, Bjoras M, Boe SO, Simonsen A: Autophagy contributes to therapy-induced degradation of the PML/RARA oncoprotein. Blood 2010;116:2324-2331.

24 Wang Z, Cao L, Kang R, Yang M, Liu L, Zhao Y, Yu Y, Xie M, Yin X, Livesey KM, Tang D: Autophagy regulates myeloid cell differentiation by p62/SQSTM1-mediated degradation of PML-RARalpha oncoprotein. Autophagy 2011;7:401-411. 


\section{Cellular Physiology Cell Physiol Biochem 2018;48:2286-2301 and Biochemistry Published online:6 6 August, $2018 \quad \begin{aligned} & \text { DOI 10159/2018 The Author(s). Published by S. Karger AG, Basel } \\ & \text { www.karger.com/cpb }\end{aligned}$ \\ Wu et al.: Mechanism of Matrine on Differentiation Recovery of ATRA-Resistant APL \\ Cells}

25 Trocoli A, Bensadoun P, Richard E, Labrunie G, Merhi F, Schlafli AM, Brigger D, Souquere S, Pierron G, Pasquet JM, Soubeyran P, Reiffers J, Segal-Bendirdjian E, Tschan MP, Djavaheri-Mergny M: p62/SQSTM1 upregulation constitutes a survival mechanism that occurs during granulocytic differentiation of acute myeloid leukemia cells. Cell Death Differ 2014;21:1852-1861.

-26 Gonzalez-Rodriguez A, Mayoral R, Agra N, Valdecantos MP, Pardo V, Miquilena-Colina ME, Vargas-Castrillon J, Lo Iacono O, Corazzari M, Fimia GM, Piacentini M, Muntane J, Bosca L, Garcia-Monzon C, Martin-Sanz P, Valverde AM: Impaired autophagic flux is associated with increased endoplasmic reticulum stress during the development of NAFLD. Cell Death Dis 2014;5:e1179.

-27 Shan ZL, Zhong L, Xiao CL, Gan LG, Xu T, Song H, Yang R, Li L, Liu BZ: Shikonin suppresses proliferation and induces apoptosis in human leukemia NB4 cells through modulation of MAPKs and cMyc. Mol Med Rep 2017;16:3055-3060.

28 Sato T, Okumura F, Iguchi A, Ariga T, Hatakeyama S: TRIM32 promotes retinoic acid receptor alphamediated differentiation in human promyelogenous leukemic cell line HL60. Biochem Biophys Res Commun 2012;417:594-600.

29 Cai R, Dai BB, Li K, Wang HJ, Xu WR, Wang JM, Lu J: Promotive effect of C/EBPepsilon overexpression on differentiation of human myelomonocytic leukemia cell line U-937. Ai Zheng 2006;25:1368-1373.

-30 Battle TE, Frank DA: STAT1 mediates differentiation of chronic lymphocytic leukemia cells in response to Bryostatin 1. Blood 2003;102:3016-3024.

-31 Parrella E, Gianni M, Cecconi V, Nigro E, Barzago MM, Rambaldi A, Rochette-Egly C, Terao M, Garattini E: Phosphodiesterase IV inhibition by piclamilast potentiates the cytodifferentiating action of retinoids in myeloid leukemia cells. Cross-talk between the cAMP and the retinoic acid signaling pathways. J Biol Chem 2004;279:42026-42040. 